\title{
CFD-Based Performance Analysis and Experimental Investigation of Design Factors of Vertical Axis Wind Turbines under Low Wind Speed Conditions in Thailand
}

\author{
Suchaya Unsakul, Chaianant Sranpat, Pongchalat Chaisiriroj, Thananchai Leephakpreeda* \\ School of Manufacturing Systems and Mechanical Engineering, Sirindhorn International Institute of Technology, Thammasat \\ University, Pathum Thani, Thailand \\ Email: *thanan@siit.tu.ac.th
}

How to cite this paper: Unsakul, S., Sranpat, C., Chaisiriroj, P. and Leephakpreeda, T. (2017) CFD-Based Performance Analysis and Experimental Investigation of Design Factors of Vertical Axis Wind Turbines under Low Wind Speed Conditions in Thailand. Journal of Flow Control, Measurement \& Visualization, 5, 86-98. https://doi.org/10.4236/jfcmv.2017.54007

Received: June 23, 2017

Accepted: October 13, 2017

Published: October 16, 2017

Copyright (ㅇ 2017 by authors and Scientific Research Publishing Inc. This work is licensed under the Creative Commons Attribution International License (CC BY 4.0).

http://creativecommons.org/licenses/by/4.0/ (c) (i) Open Access

\begin{abstract}
This paper presents effects of design factors on mechanical performance of Vertical Axis Wind Turbines (VAWTs), and an experimental investigation of optimal VAWT performance under low wind speed conditions in Thailand. Design factors include types of wind turbines, number of blades, types of materials, height-to-radius ratios, and design modifications. Potential VAWT models with different design factors are numerically analyzed within a virtual wind tunnel at various wind speeds by utilizing Xflow ${ }^{\mathrm{TM}}$ Computational Fluid Dynamics (CFD) software. The performance curves of each VAWT are obtained as plots of power coefficients against tip speed ratios. It is found that the type of wind turbine, number of blades, and height-to-radius ratio have significant effects on mechanical performance whereas types of materials result in shifts of operating speeds of VAWTs. Accordingly, an optimal VAWT prototype is developed to operate under actual low speed wind conditions. The performance curve from experimental results agrees with the CFD results. The proposed methodology can be used in the computer design of VAWTs to improve mechanical performance before physical fabrication.
\end{abstract}

\section{Keywords}

Vertical Axis Wind Turbine, CFD Analysis, Experimental Technique, Low Wind Speed, Power Coefficient, Tip Speed Ratio

\section{Introduction}

Wind has been an important energy source due to its renewability and sustainability. There are two types of wind turbines: Vertical Axis Wind Turbines 
(VAWTs) and Horizontal Axis Wind Turbines (HAWTs), which are commonly used to convert the kinetic energy of wind into mechanical energy of wind turbines. In this work, VAWTs have efficiently omnidirectional capability to harvest wind energy at low wind speed conditions.

For Thailand, wind speeds are statistically recorded up to $6 \mathrm{~m} / \mathrm{s}$ at a height of $40 \mathrm{~m}$ [1]. VAWTs with wind boosters are highly suitable under the low wind speed conditions of Thailand [2]. For standalone VAWTs, there were some sustainable developments of Savonius rotors for wind turbines to improve power generation in the past [3] [4] [5] [6]. Recently, Schubel and Crossley reviewed aerodynamic designs of turbine blades for potentials of mechanical improvement [7]. Mahmound et al. studied the improvement of Savonius VAWT performance [8]. Different geometries of Savonius VAWT are investigated in order to determine the most effective conditions. D'Alessandro and et al. derived mathematical models for determining the mechanical performance of wind turbines [9]. It was reported that the mathematical models led to efficient rotors for VAWTs. Salyers performed experimental investigations of aerodynamic improvement for VAWTs [10].

Bhutta et al. reviewed previous works, which are related to various configurations and design techniques for VAWTs [11]. In wind engineering research, there are many attempts of improving the mechanical performance of Savonius rotors in various approaches. In an experimental investigation [12], the number of blades is increased for multiple blades in different operating conditions under ocean flows. With design modification of blades, a helical Savonius VAWT, twisted $90^{\circ}$, was proposed to eliminate the excessive shaking of blades [13]. The twisted angle of a Savonius VAWT blade is numerically optimized for maximum power generation [14] [15]. The modified configuration of blades with an overlap at the center was introduced to improve mechanical torque [16] [17]. Also, the number of stages has influences on the aerodynamic behavior of turbulent airflow around Savonius VAWTs where the power coefficient increases as the number of stages increases [18]. Additionally, a cluster of two and three VAWTs was investigated to enhance mechanical power generation, compared to a standalone VAWT [19]. The optimum gap distance is experimentally determined to avoid the wake of upstream VAWTs.

Those studies yield design knowledge for optimizing VAWTs with high efficiency. However, there is a deficiency of quantitative relationships between design factors and mechanical performance of VAWTs. Design factors of VAWTs are types (Savonius and Darrieus), number of turbine blades, types of materials, height to radius ratios, and design modifications.

In this study, VAWTs with various design factors are numerically simulated within virtual wind tunnels at different wind speeds by utilizing $\mathrm{Xflow}^{\mathrm{TM}} \mathrm{Com}$ putational Fluid Dynamics (CFD) software. Correspondingly, the power coefficients are obtained with respect to tip speed ratios. An optimal design of VAWTs is chosen according to those analytical experiences. For experimental investigation, the VAWT is fabricated accordingly, and it is operated under actual 
low wind speed conditions.

\section{Methodology}

In this study, each VAWT model is developed for a given geometry by using computer-aided design software, such as AutoCAD ${ }^{\mathrm{TM}}$ and SolidWorks ${ }^{\mathrm{TM}}$. Except for types of materials, design factors, such as types of wind turbines, number of turbine blades, height to radius ratios, and design modification, can be varied in this step. The types of materials are adjusted by setting the values of density in CFD simulation. Under a virtual wind tunnel, the VAWTs are simulated to investigate effects of the design factors on mechanical performance under low wind speed conditions from $1 \mathrm{~m} / \mathrm{s}$ to $6 \mathrm{~m} / \mathrm{s}$.

\subsection{Xflow ${ }^{\mathrm{TM}}$ CFD-Based Setup}

For CFD-based case studies, Figure 1 illustrates a geometrical setup of rigidbody dynamics with fixed translation and y-axis rotational constraints. All types of VAWTs in this work have a swept area of $0.125 \mathrm{~m}^{2}$. The arrow heads indicate the flow direction of air within a virtual wind tunnel at a given wind speed. For the boundary conditions, a uniform flow of air arrives at the entrance through the virtual wind tunnel with a constant speed. A VAWT, which is installed within the virtual wind tunnel, has no rotation initially. Discretization parameters, such as number, grid resolution, and airflow conditions, are set up in the CFD software and listed in Table 1 . The types of materials are defined from different densities of $1000 \mathrm{~kg} / \mathrm{m}^{3}, 2440 \mathrm{~kg} / \mathrm{m}^{3}$, and $3500 \mathrm{~kg} / \mathrm{m}^{3}$ in this work.

Table 1. CFD setup and air properties.

\begin{tabular}{|c|c|c|}
\hline Parameters & Values & Units \\
\hline Virtual Wind Tunnel Dimension $(\mathrm{x}, \mathrm{y}, \mathrm{z})$ & $(2,0.7,2)$ & $\mathrm{m}$ \\
\hline \multicolumn{3}{|l|}{ Air Properties } \\
\hline Molecular Weight & 28.996 & $\mathrm{~g} / \mathrm{mol}$ \\
\hline Density & 1.255 & $\mathrm{~kg} / \mathrm{m}^{3}$ \\
\hline Temperature & 288.15 & K \\
\hline Viscosity & $1.7894 \times 10^{-5}$ & $\mathrm{~m}^{2} / \mathrm{s}$ \\
\hline Flow Model & \multicolumn{2}{|c|}{ Single phase } \\
\hline Analysis Type & \multicolumn{2}{|c|}{ External flow } \\
\hline Thermal Model & \multicolumn{2}{|c|}{ Isothermal } \\
\hline Turbulence Model & \multicolumn{2}{|c|}{ Wall-adapting local-Eddy } \\
\hline Turbulence Intensity & \multicolumn{2}{|c|}{$3.5 \%$} \\
\hline Refine Algorithm & \multicolumn{2}{|c|}{ Adaptive refinement } \\
\hline Number of grids & \multicolumn{2}{|c|}{$1,200,000$} \\
\hline Grid model & \multicolumn{2}{|c|}{ Octree-like grid } \\
\hline Resolved Scale (grid size of wind tunnel) & \multicolumn{2}{|c|}{$0.01 \mathrm{~m}$} \\
\hline Target Resolved Scale (grid size near wind turbine) & \multicolumn{2}{|c|}{$0.01 \mathrm{~m}$} \\
\hline
\end{tabular}




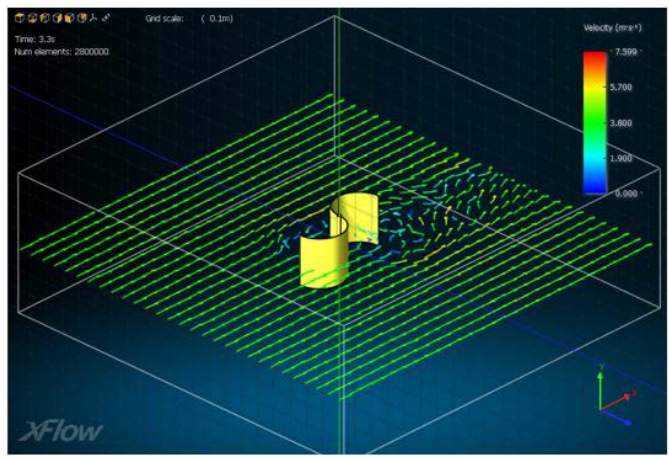

(a)

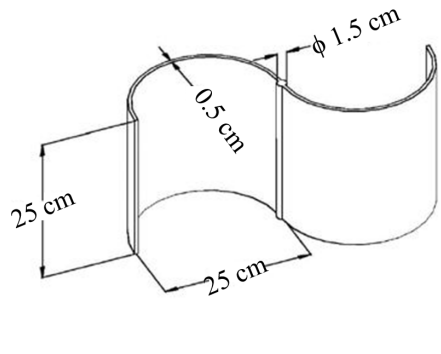

(b)

Figure 1. CFD setup: (a) wind turbine within virtual wind tunnel and (b) dimensions of VAWT.

\subsection{Dimensionless Analysis of Mechanical Performance}

In CFD-based analysis, the VAWT are simulated at various wind speeds with constant external torsional loads. The angular speeds of the VAWT are recorded under steady state conditions where the external torsional load is equal to the torque of the VAWT shaft. The mechanical power can be determined from multiplication of angular speed and torque. The performance curve is defined between the power coefficient and the tip speed ratio. The tip speed ratio can be determined by:

$$
\lambda=\frac{\omega R}{V}
$$

where $\lambda$ is the tip speed ratio, $\omega$ is the angular speed of wind turbine $(\mathrm{rad} / \mathrm{s}), R$ is the radius of wind turbine $(\mathrm{m})$ and $V$ is the wind speed $(\mathrm{m} / \mathrm{s})$.

The power coefficient is defined as the ratio of mechanical power of wind turbine to wind power as expressed in Equation (2).

$$
C_{p}=\frac{P_{t}}{P_{w}}
$$

where $C_{p}$ is the power coefficient, $P_{t}$ is the mechanical power of turbine $(W)$, and $P_{w}$ is the wind power $(W)$.

\subsection{Experimental Setup}

In this section, an optimal VAWT design is chosen, according to analytical studies. The schematic diagram of the VAWT model is a $90^{\circ}$ twisted two-layer Savonius-type VAWT with covers, as shown in Figure 2. The VAWT model is made of acrylic material, where the shape and dimension are identical to the optimal CFD model. Magnetic levitation is applied at the two supporting joints so as to minimize coulomb friction, as seen in Figure 3. The structure is placed under actual wind conditions. The wind speeds are measured by a hot-wire anemometer, while the angular speeds of the VAWT are detected by an encoder for the determination of power coefficient and tip speed ratio. The mechanical 

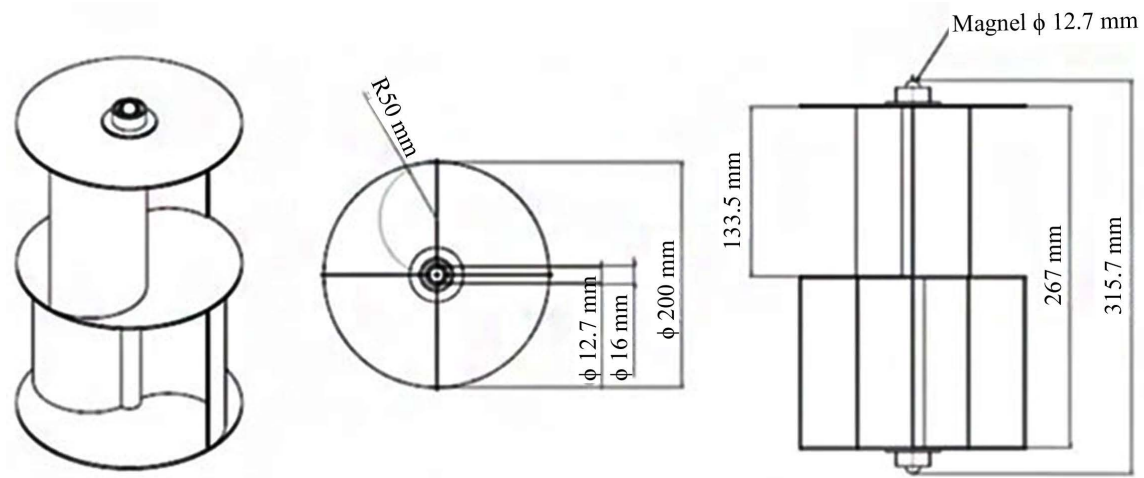

Figure 2. $90^{\circ}$ twisted two-layer Savonius-type VAWT with cover.

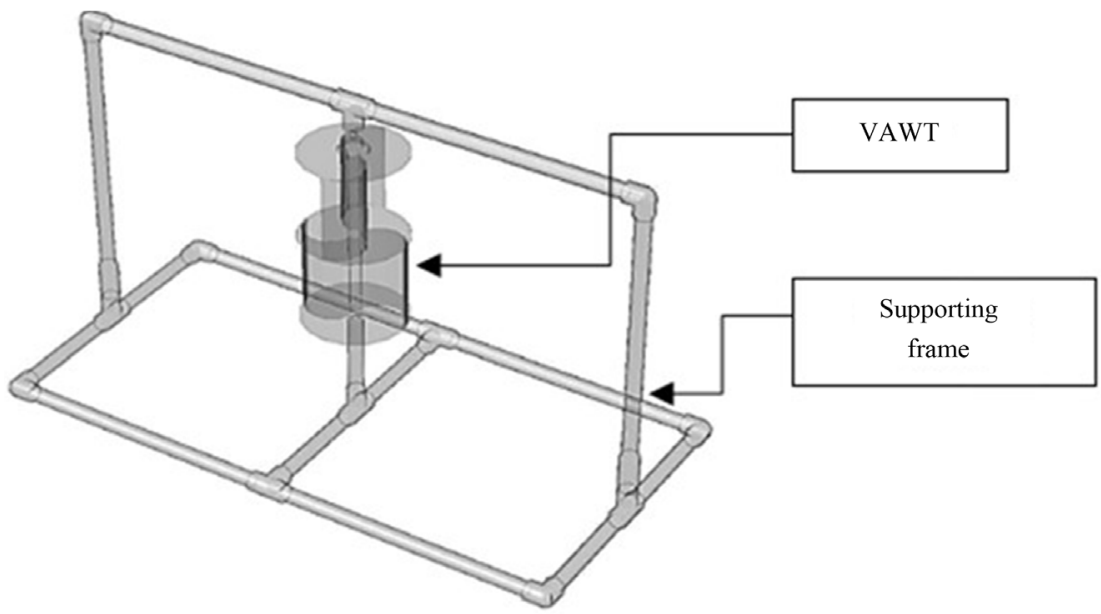

Figure 3. Experiment of optimal VAWT under actual wind conditions.

power of a VAWT is determined from the rate of change in kinetic energy of the VAWT shaft. The performance curve from CFD plots of the power coefficient against tip speed ratio is compared with the experimental results in Section 3.

\section{Results and Discussion}

In this section, CFD-based studies of mechanical performances are presented with respect to design factors: material types, number of turbine blades, height to radius ratios, design modification, and turbine patterns.

\subsection{Effects of Material Types}

A Savonius-type VAWT is set up within a virtual wind tunnel, as shown in Figure 1. The number of grids is an important factor for accuracy of numerical results. It is found that the greater the number of grids, the higher the accuracy. However, the computational time increases exponentially when the number of grids increases linearly. The number of grids in this study is chosen in each case if an increase of the number of grids does not significantly change the simulated results.

The values of density are $1000 \mathrm{~kg} / \mathrm{m}^{3}$ (plastic), $2440 \mathrm{~kg} / \mathrm{m}^{3}$ (glass fiber), and 
$3500 \mathrm{~kg} / \mathrm{m}^{3}$ (metal) for the three case studies. Figure 4 shows plots of power coefficients against tip speed ratios of all three models. It is observed that a given geometry of VAWTs yields different curves of mechanical performance where the wind turbines are made of different materials. The operating range of angular speed is varied according to the inertia of the VAWTs. The wind turbine with high density rotates more slowly than low density while the same turbine torques, due to wind, are applied to the three VAWTs. In turn, the power coefficient of the wind turbine with low density is higher than high density.

\subsection{Number of Turbine Blades}

Savonius-type VAWTs models, with two, three, and four blades, are used in CFD simulations under various wind conditions. It is seen from Figure 5 that a VAWT with two blades yields the largest power coefficients among the three models. Also, a wide range of tip speed ratios is found from the VAWTs with two blades. The VAWTs can rotate fast with high efficiency.

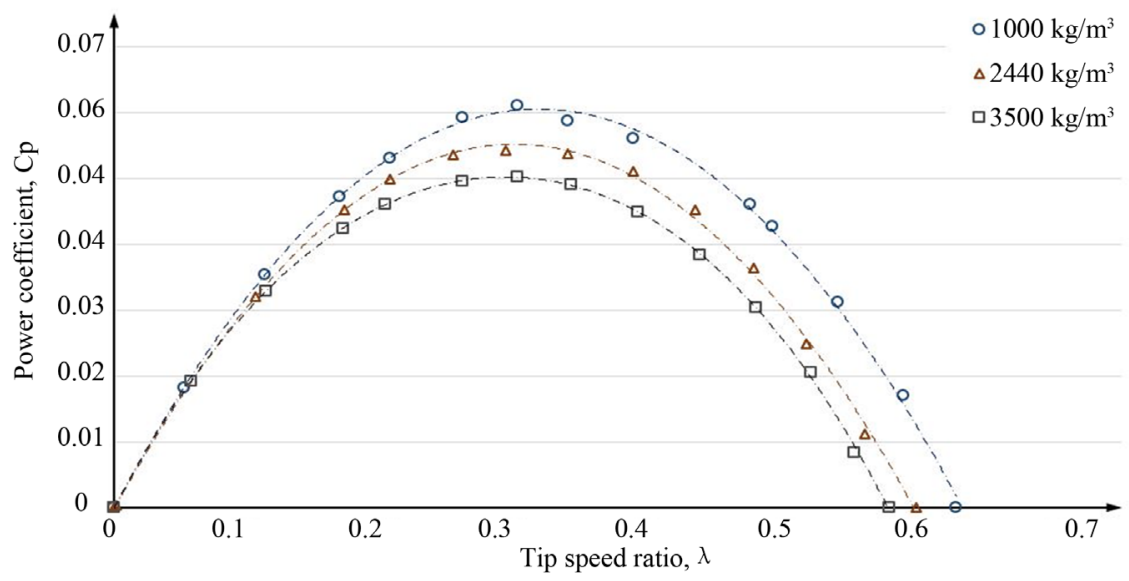

Figure 4. Power coefficient curve of wind turbines made of different materials.

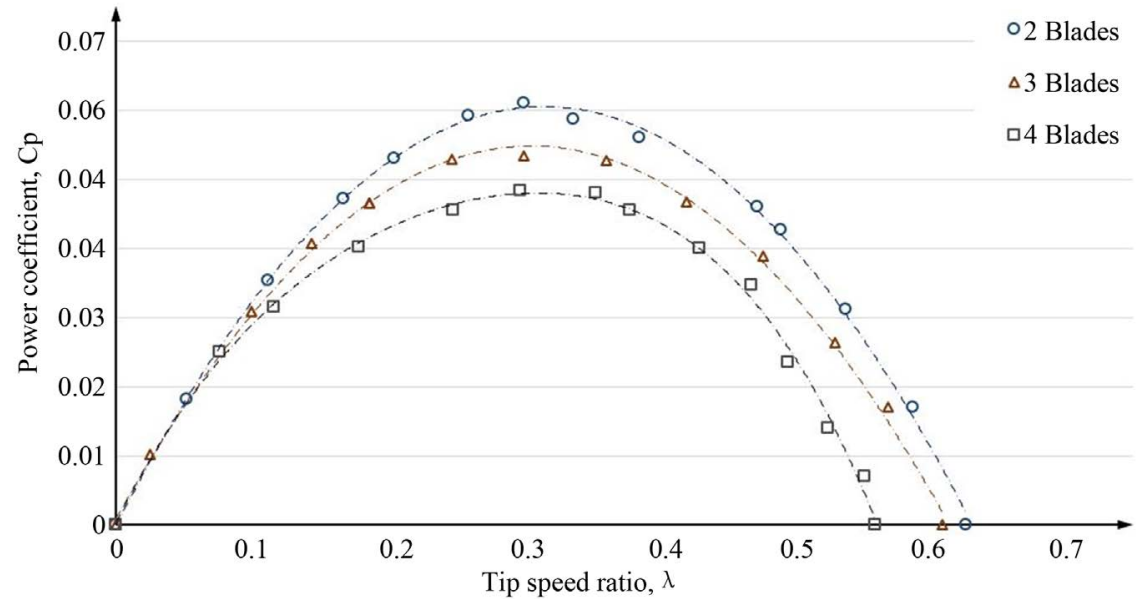

Figure 5. Power coefficient curves of Savonius-type VAWTs with different number of blades. 


\subsection{Height to Radius Ratios}

The radius of each model is adjusted with respect to a unity height such a way that the swept area remains constant. As shown in Figure 6, the power coefficient of VAWT increases rapidly as the radius of the VAWT blade increases. The torque of a VAWT increasingly produces mechanical power. This reaches a maximum value at a ratio of height to radius of around 1:0.375. After that point, it decreases due to a high moment of inertia with slow rotation.

\subsection{Design Modifications}

There are three interesting design modifications: helix pattern, cover-added pattern, and double layer pattern, as shown in Figure 7. From Figure 8, the VAWTs with helix patterns in both $90^{\circ}$ and $180^{\circ}$ twisting angles yield a decrease of ability to harvest wind energy while rotating. The VAWTs with cover-added pattern are capable of taking up wind energy better than the conventional pattern. The power coefficients of the VAWTs with a cover-added pattern and double layers slightly decrease due to low height to radius ratio. However, the VAWTs with a cover-added pattern and perpendicular double layers can perform at maximum efficiency of mechanical work, among these design modification.

\subsection{Darrieus-Type Turbine}

Figure 9(a) shows a type of Darrieus VAWT, which is varied with a different height to radius ratio. From Figure 9(b), the mechanical performance of Darrieus VAWTs is better when the height is less than the width. It is observed that the power coefficient is low at low tip speed ratio since the Darriues VAWT has inherently a low torque for rotation. In fact, it requires a driving device for starting rotation. After tuning to high tip speed ratio, the Darrieus VAWT efficiently produces mechanical work while the tip of the VAWT blade runs faster

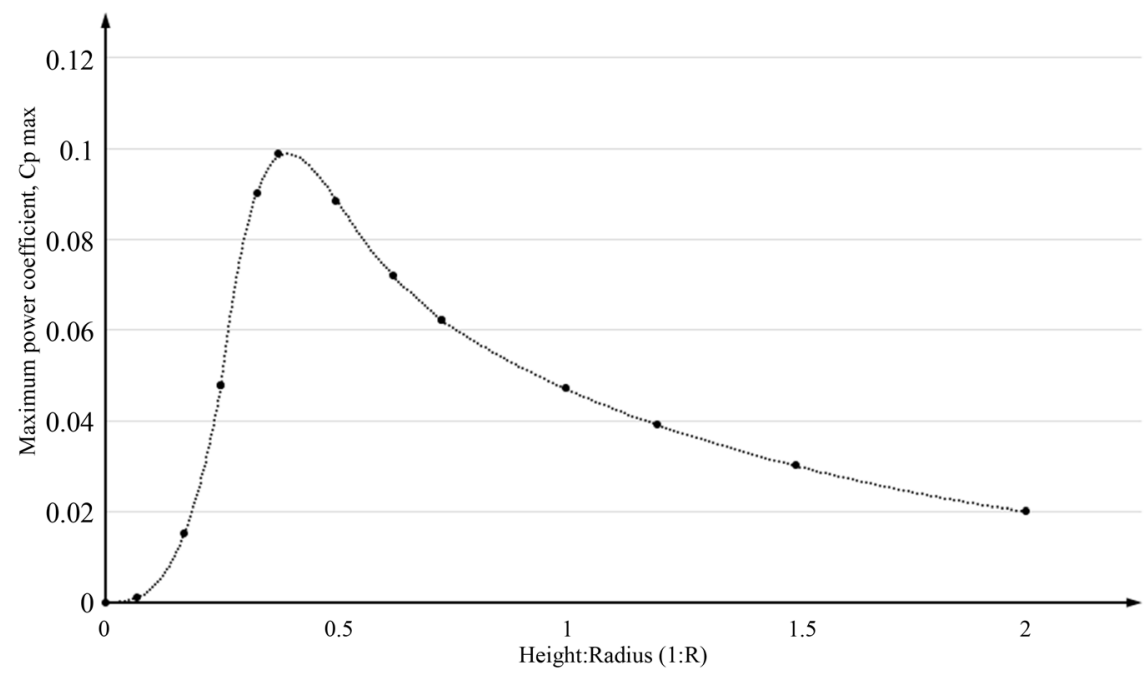

Figure 6. Plot of power coefficient against unity Height to Radius ratio (1:R). 


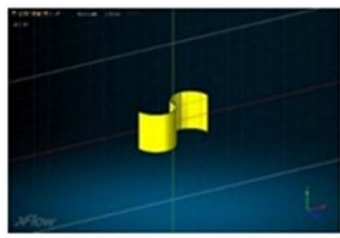

(a)

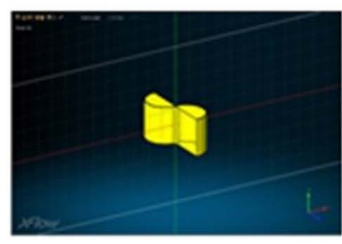

(d)

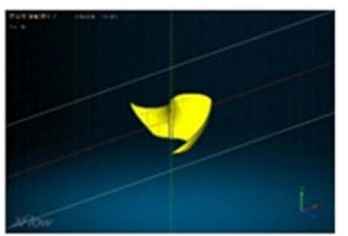

(b)

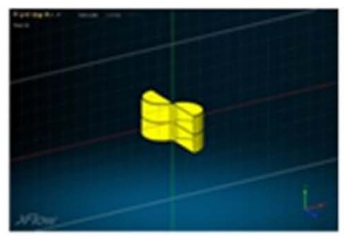

(e)

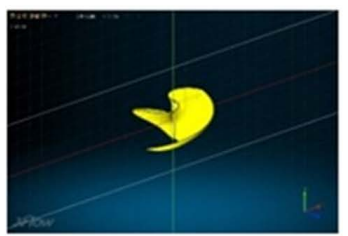

(c)

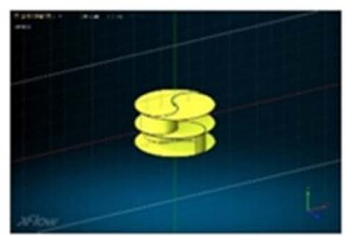

(f)

Figure 7. Savonius design with (a) conventional pattern (b) Helix $90^{\circ}$ pattern (c) Helix $180^{\circ}$ pattern (d) Cover-added pattern (e) Cover-added pattern with double layers and (f) Perpendicular double layers.

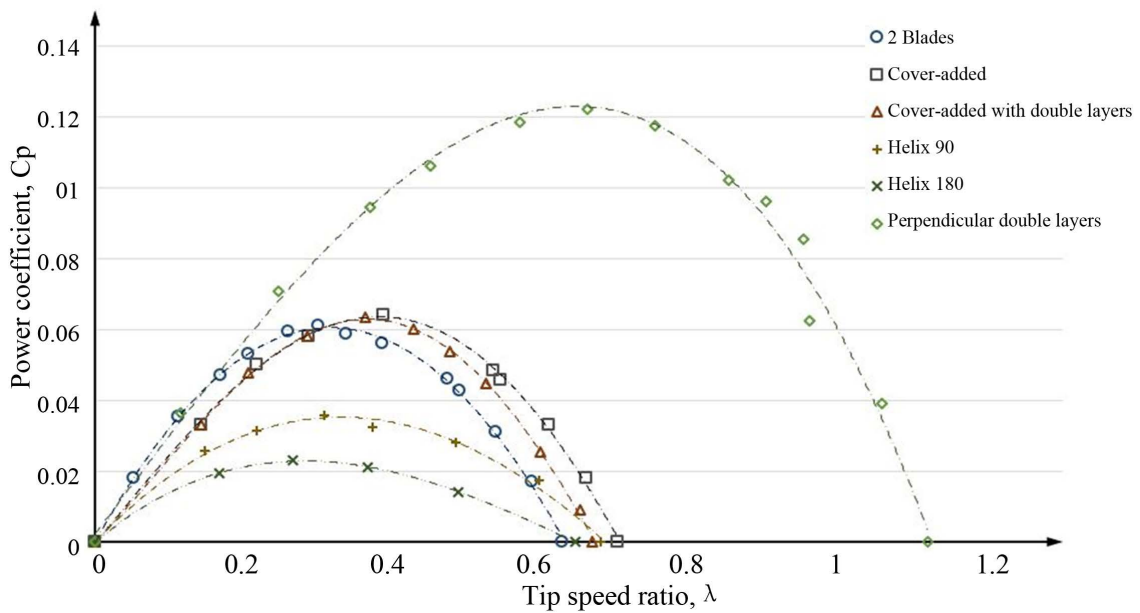

Figure 8. Mechanical performances of different design modifications.

than the wind speed. The value of the power coefficient reaches a maximum. However, if the torsional loading on the VAWT is less (or more), the power coefficient declines rapidly. A design for power generation must be considered for a suitable load torque in this case. Furthermore, the power coefficient of Darrieus VAWTs is higher than Savonius VAWTs, while they also run at a higher tip speed ratio.

\subsection{CFD Analysis and Experiment of Optimal Model}

The design factors have been studied in previous sections. It is found that the Savonius VAWT with two blades has a geometric advantage in suitably harvesting wind energy in most rotational positions of the VAWT. However, there is a singularity in the VAWT-blade position, parallel to wind flow. Therefore, another VAWT is installed by a position of the VAWT blade, perpendicular to the other. This $90^{\circ}$ twisted two-layer Savonius VAWT yields the highest power coefficients among other studied VAWT. The Darriues VAWT is incapable of 


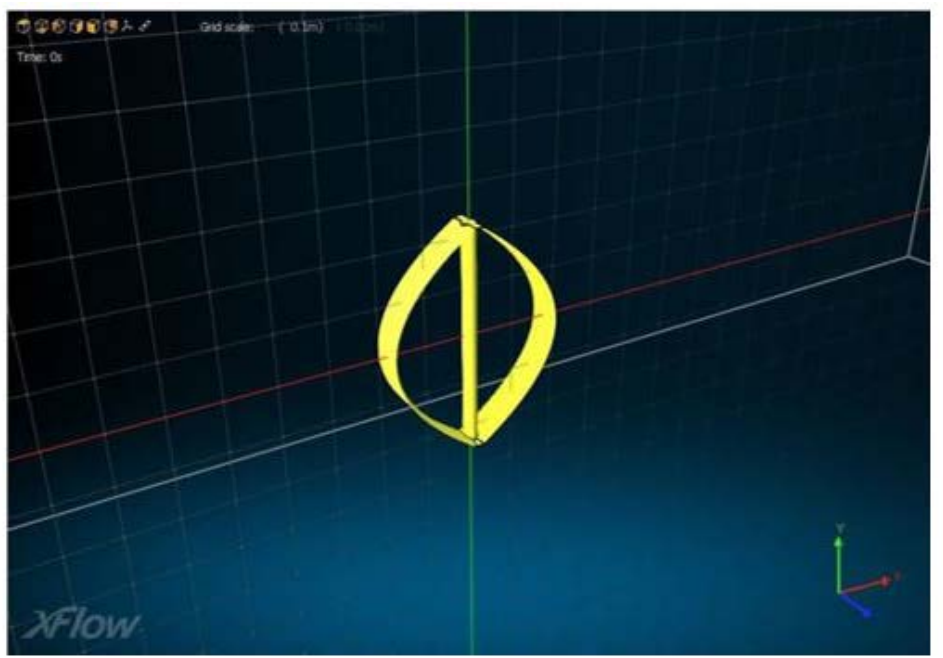

(a)

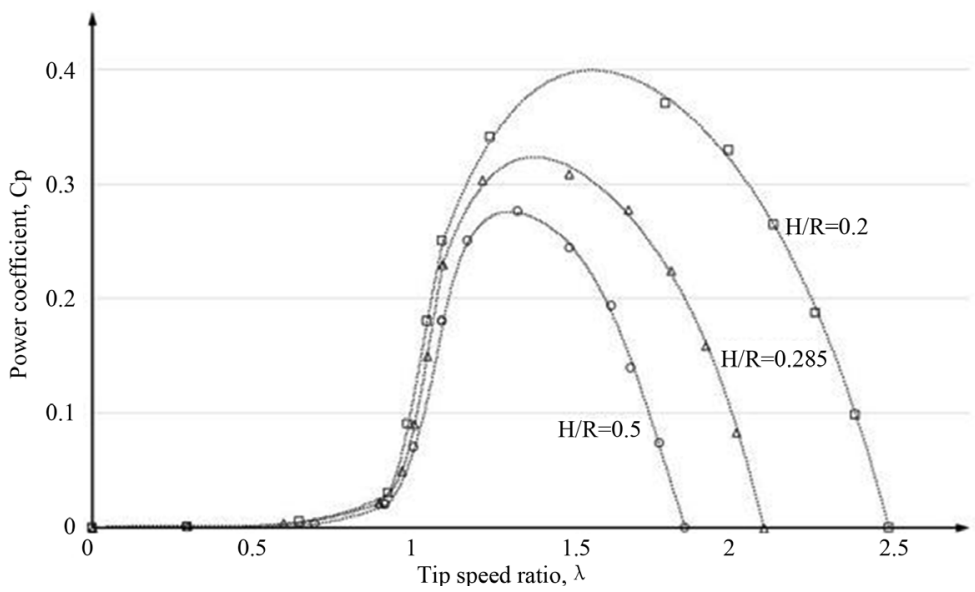

(b)

Figure 9. Darrieus-type VAWTs: (a) model and (b) mechanical performances.

starting to rotate by itself, especially under low wind speed conditions. Figure 10 shows mechanical performance of an optimal VAWT, shown in Figure 2. The VAWT is simulated under various wind speeds and torsional loads within a virtual wind tunnel of X-Flow ${ }^{\mathrm{TM}}$. The power coefficient is varied according to tip speed ratios. It is observed that the power coefficient increases as the tip speed ratio increases. Once it reaches a maximum value of $3.51 \%$ at around a tip speed ratio of 0.55 , it decreases to zero, where the VAWT is run under no-load conditions. It should be noted that the power coefficient is lower than the commonly-known values of 0.15 to 0.2 since dimensions and geometry of wind turbines in this work are different from other turbines in literature. For example, influence of the end plates on both sides of the rotor causes different turbulent effects.

For an experiment, the VAWT is installed under actual wind conditions. Angular speeds of the VAWT are measured by an electric encoder, while the wind speed is measured by a hot-wire anemometer. In Figure 11, plots of the angular 


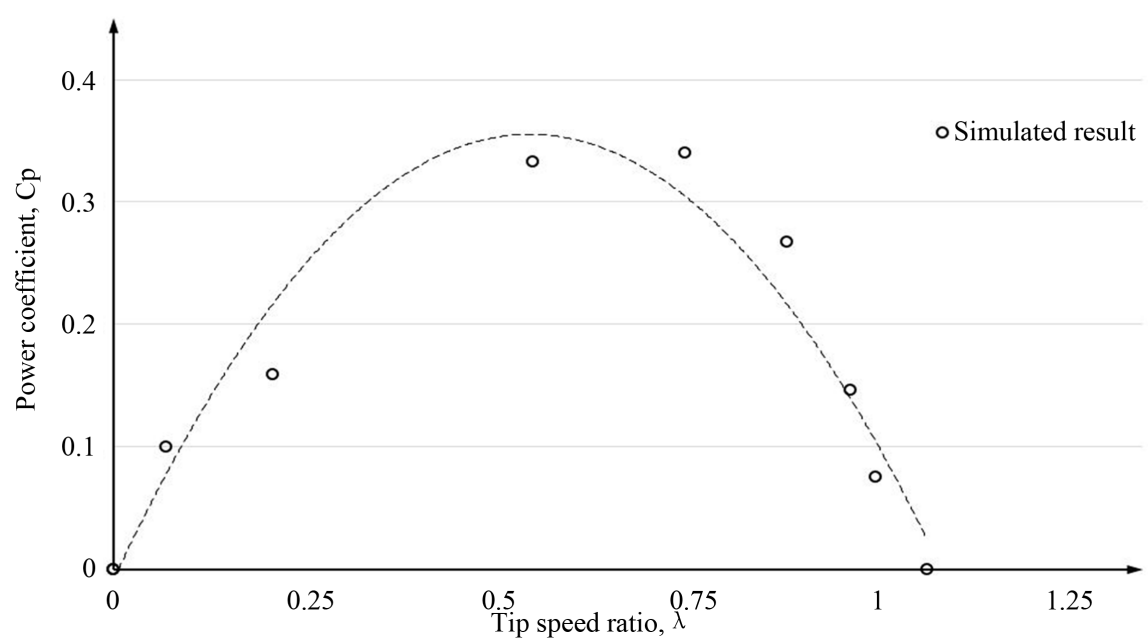

Figure 10. Plots of power coefficient curve of VAWT from CFD simulation.

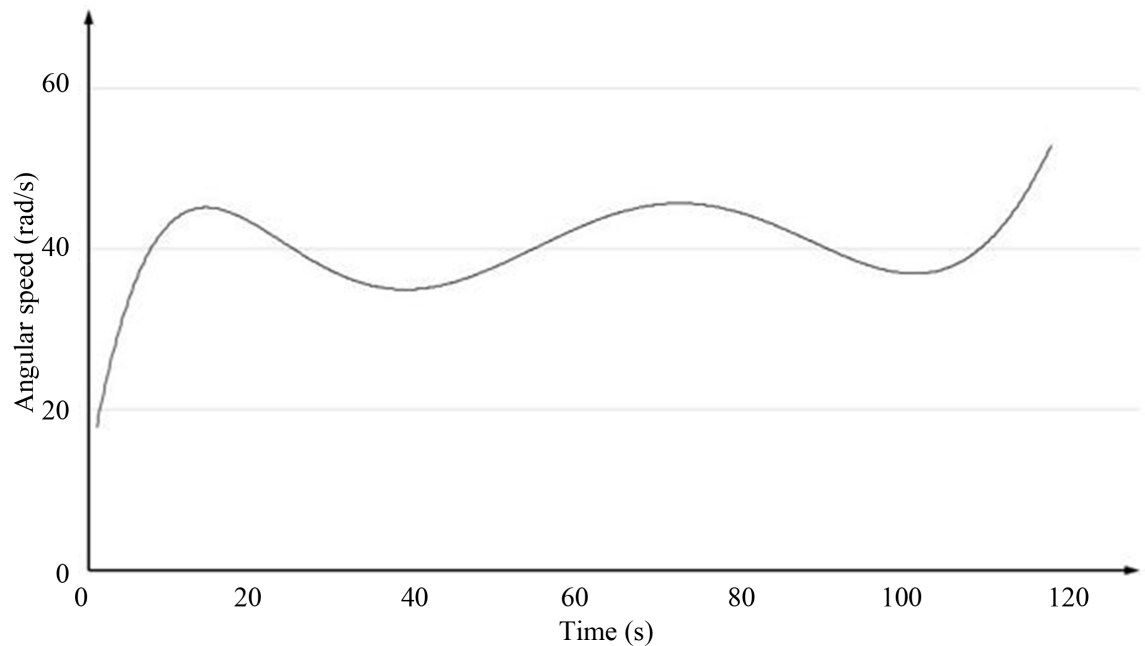

(a)

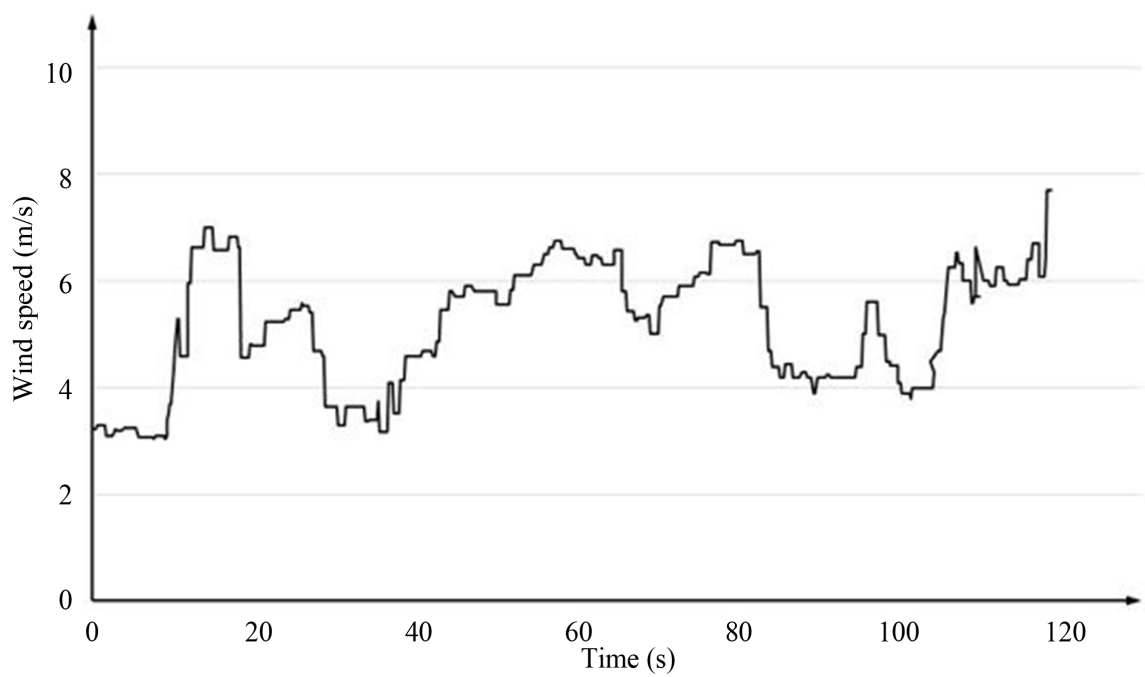

(b)

Figure 11. Plots of measurement data against time: (a) Angular speed of VAWT and (b) Wind speed. 
speeds and wind speeds are illustrated with respect to time. The mean wind speed and standard deviation are $5.32 \mathrm{~m} / \mathrm{s}$ and $1.12 \mathrm{~m} / \mathrm{s}$, respectively. They are used to determine the tip speed ratios in Equation (1). Accordingly, the power of a VAWT is determined by the rate of change in kinetic energy. The power coefficient is calculated by using Equation (2). In Figure12, the performance curve of CFD results are fitted well to the power coefficients against tip speed ratios, which are obtained from the experiment. The averaged relative difference between experimental data and CFD results are $3.30 \%$. The deviations may be caused by uncertainties in measurement, airflow, and/or VAWT structure. However, it is confirmed that an optimal VAWT design can be obtained from the CFD analysis before physical fabrication. The power coefficient against tip speed ratio is used as a performance curve in power generation under various wind speed conditions.

\section{Conclusion}

Effects of design factors: material types, number of turbine blades, height to radius ratios, design modification, and turbine patterns, are analyzed by using CFD-based simulations within a virtual wind tunnel. The mechanical performances of VAWTs under low speed wind conditions are determined from plots of power coefficient against tip speed ratio. The Savonius-type VAWT can be selected for high torque at low angular speeds while the Darrieus-type VAWT can be chosen for power generation at high angular speeds. A number of blades and height to radius ratio have significant effects on operating conditions of rotation due to inertia. In this study, the Savonius-type VAWT, with a coveradded pattern and perpendicular double layers, yields great mechanical performance. The CFD results of the performance curve have good agreement with the experimental results of the optimal VAWT, which is operated under actual wind

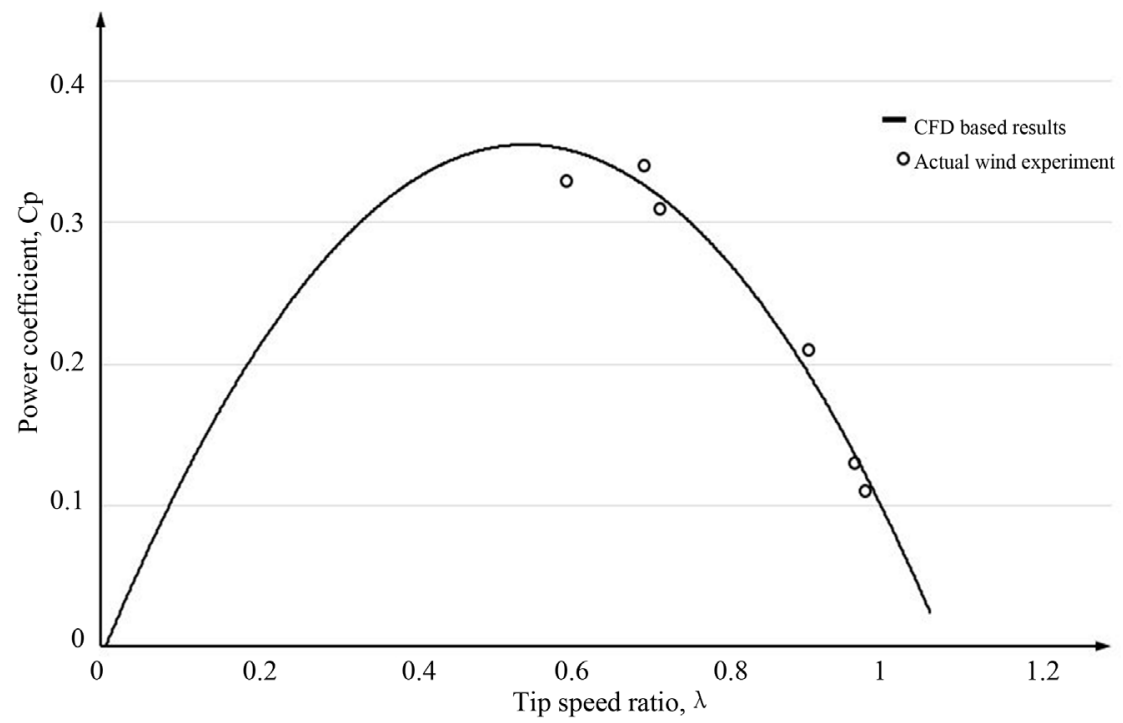

Figure 12. Comparison between experimental results and CFD results. 
conditions. The proposed methodology can be used to find the optimal VAWT from CFD analysis before physical fabrication.

\section{References}

[1] Quan, P. and Leephakpreeda, T. (2015) Assessment of Wind Energy Potential in the Central Region of Thailand: A Wind Analysis. Proceedings of 2015 International Conference on Alternative Energy in Developing Countries and Emerging Economies (2015 AEDCEE), Bangkok, 28-29 May 2015, 269-270.

[2] Korprasertsak, N. and Leephakpreeda, T. (2016) Analysis and Optimal Design of Wind Boosters for Vertical Axis Wind Turbines at Low Wind Speed. Journal of Wind Engineering and Industrial Aerodynamics, 159, 9-18. https://doi.org/10.1016/j.jweia.2016.10.007

[3] Sheldahl, R.E., Feltz, L.V. and Blackwell, B.F. (1978) Wind Tunnel Performance Data for Two- and Three-Bucket Savonius Rotors. Journal of Energy, 2, 160-164. https://doi.org/10.2514/3.47966

[4] Ushiyama, I. and Nagai, H. (1988) Optimum Design Configurations and Performance of Savonius Rotors. Wind Engineering, 12, 59-75

[5] Fujisawa, N. (1992) On the Torque Mechanism of Savonius Rotors. Journal of Wind Engineering and Industrial Aerodynamics, 40, 277-292. https://doi.org/10.1016/0167-6105(92)90380-S

[6] Modi, V.J. and Fernando, M.S.U.K. (1989) On the Performance of the Savonius Wind Turbine. Journal of Solar Energy Engineering, 111, 71-81. https://doi.org/10.1115/1.3268289

[7] Schubel, P.J. and Crossley, R.J. (2012) Wind Turbine Blade Design. Energies, 5, 3425-3449. https://doi.org/10.3390/en5093425

[8] Mahmoud, N.H., EI-Haroun, A.A., Wahba, E. and Nasef, M.H. (2012) An Experimental Study on Improvement of Savonius Rotor Performance. Alexandria Engineering Journal, 51, 19-25. https://doi.org/10.1016/j.aej.2012.07.003

[9] D’Alessandro, V., Montelpare, S., Ricci, R. and Secchiaroli, A. (2010) Unsteady Aerodynamics of a Savonius Wind Rotor: A New Computation Approach for the Simulation of Energy Performance. Energy, 35, 3349-3363. https://doi.org/10.1016/j.energy.2010.04.021

[10] Salyers, T.E. (2016) Experimental and Numerical Investigation of Aerodynamic Performance for Vertical-Axis Wind Turbine Models with Various Blade Designs. College of Graduate Studies, Georgia Southern University, Georgia.

[11] Bhutta, M.M.A., Hayat, N., Farooq, A.U., Ali, Z., Jamil, S.R. and Hussain, Z. (2012). Vertical Axis wind Turbine-A Review of Various Configurations and Design Techniques. Renewable and Sustainable Energy Reviews, 16, 1926-1939. https://doi.org/10.1016/j.rser.2011.12.004

[12] Tutar, M. and Veci, I. (2016) Performance Analysis of a Horizontal Axis 3-Bladed Savonius Type Wave Turbine in an Experimental Wave Flume (EWF). Renewable Energy, 86, 8-25. https://doi.org/10.1016/j.renene.2015.07.079

[13] Kumar, D. and Sarkar, S. (2017) Modeling of Flow-Induced Stress on Helical Savonius Hydrokinetic Turbine with the Effect of Augmentation Technique at Different Operating Conditions. Renewable Energy, 111, 740-748. https://doi.org/10.1016/j.renene.2017.05.006

[14] Kumar, A. and Saini, R.P. (2017) Performance Analysis of a Savonius Hydrokinetic Turbine Having Twisted Blades. Renewable Energy, 108, 502-522. https://doi.org/10.1016/j.renene.2017.03.006 
[15] Kumar, A. and Saini, R.P. (2017) Performance Analysis of a Single Stage Modified Savonius Hydrokinetic Turbine Having Twisted Blades. Renewable Energy, 113, 461-478. https://doi.org/10.1016/j.renene.2017.06.020

[16] Kamoji, M.A., Kedare, S.B. and Prabhu, S.V. (2009) Experimental Investigations on Single Stage Modified Savonius Rotor. Applied Energy, 86, 1064-1073. https://doi.org/10.1016/j.apenergy.2008.09.019

[17] Akwa, J.V., Alves da Silva Jr., G. and Petry, A.P. (2012) Discussion on the Verification of the Overlap Ratio Influence on Performance Coefficients of a Savonius Wind Rotor Using Computational Fluid Dynamics. Renewable Energy, 38, 141-149. https://doi.org/10.1016/j.renene.2011.07.013

[18] Frikha, S., Driss, Z., Ayadi, E., Masmoudi, Z. and Abid, M.S. (2016) Numerical and Experimental Characterization of Multi-Stage Savonius Rotors. Energy, 114, 382-404. https://doi.org/10.1016/j.energy.2016.08.017

[19] Shaheen, M., El-Sayed, M. and Abdallah, S. (2015) Numerical Study of Two-Bucket Savonius Wind Turbine Cluster. Journal of Wind Engineering and Industrial Aerodynamics, 137, 78-89. https://doi.org/10.1016/j.jweia.2014.12.002 